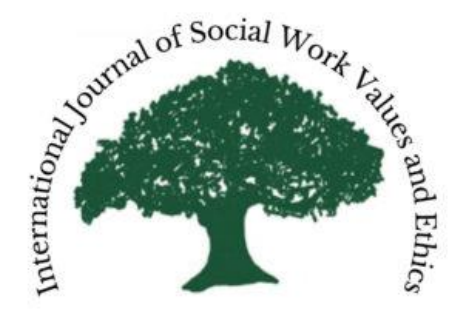

International Journal of Social Work Values and Ethics

Volume 19, Number 1 (2022)

ISSN: 2790-6345

DOl: 10.55521/10-019-100

www.jswve.org 


\section{The Impact of Experiential Learning on Social Work Students' Application of the NASW Code of Ethics Post-Graduation}

DOI: 10.55521/10-019-110

Erin L. Robinson, PhD, MSW, MPH

University of Missouri

robinsonel@missouri.edu

Toby Mills, MSW, LCSW

University of Missouri

millsto@mizzou.edu
Geunhye Park, MA

University of Missouri

gpmdm@mail.missouri.edu

Emily Pekarek, MSW, LMSW

University of Missouri

emilypekarek@gmail.com

Ryan Bobst, MSW, LMSW

University of lowa

bobst.ryan@gmail.com

International Journal of Social Work Values and Ethics • Volume 19(1), Copyright 2022 by IFSW This text may be freely shared among individuals, but it may not be republished in any medium without express written consent from the authors and advance notification of IFSW.

\section{Abstract}

Experiential learning techniques have the ability to prepare social work students for practice by exposing them to real world challenges and allowing them to gain hands on experience. However, little is known about the direct impact such techniques have on students' social work careers post-graduation. This study aims to fill that gap. Qualitative interviews were conducted with graduates from an undergraduate social work program $(\mathrm{N}=20)$ who 
had participated in an immersion learning course as part of their social work education. In part, this course focused on poverty, homelessness, and sexual exploitation of women. The six values of the NASW Code of Ethics and the principles based on these values were used as a framework to investigate the impact of this course. Interviews were analyzed by multiple investigators using Nvivo12. Findings indicate that experiential learning techniques, such as immersion learning, can have an impact on how students understand and apply each of the six ethical values of the Code with a generalist approach to poverty and homelessness post-graduation. Particularly, students reported an ability to better apply the values of social justice, dignity and worth of the person, importance of human relationships, and competence to their social work careers. These findings further inform social work education and reinforce the utility of experiential learning.

Keywords: Immersion learning, experiential education, BSW students, qualitative research, teaching research

\section{Review of the Literature}

According to Experiential Learning Theory (Kolb, 1984), knowledge acquisition heavily relies upon exposing the learner to concrete experiences. Through a process of reflective observation and abstract conceptualization, the learner can then develop an understanding of (or revise their current understanding of) that experience to which they can actively apply to future situations. This integrated process enables learners to develop critical thinking and self-awareness (Cleary, 2001). Roots of Kolb's Experiential Learning Theory can be traced back to John Dewey's pioneering work in active learning approaches. Dewey (1938) maintained that learning should be an experiential process in which students learn by doing, through active engagement in classroom experiences. As social work is an applied profession, experiential teaching approaches can be particularly useful in training future practitioners. Exposing students to real-world issues that challenge the social work profession, and facilitating the learning processes around those 
experiences can facilitate and reinforce critical self-discovery and understanding of the profession (Milne \& Adams, 2015; Pugh, 2014a).

\section{Experiential learning, cultural competency, and job readiness}

There is ample literature to support that experiential learning programs can be especially effective in developing cultural competency among students (Cramer et al., 2012; Dailey et al., 2016; Fineran et al., 2002; Maccio, 2011; Pugh, 2014b; Sanders et al., 2003). Saunders et al. (2015) describe cultural competence education as a journey that should be facilitated by both the social work student and the institution. Developing a strong sense of selfawareness is an integral step for students in their journey toward cultural sensitivity (Taylor \& Cheung, 2010).

Schelbe et al. (2014) describe how service-learning activities can facilitate the cultural competency process and assist students in becoming more self-aware. Experiential learning activities can also assist students in discovering their own biases towards different population groups (Pugh, 2014b; Robinson, 2018), which can impact their overall perceptions of different groups (Carey, 2007; Sanders et al., 2003). In particular, Vandsburger et al. (2010) discuss a poverty simulation activity in which students $(\mathrm{N}=101)$ were exposed to real-life hardships faced by individuals experiencing poverty. Students who participated in this simulation gained a deeper understanding of poverty and an ability to analyze the effects of poverty, which impacted their overall perceptions of people living in such circumstances (Vandsburger et al., 2010).

Experiential learning programs have also demonstrated an impact on students' perceived personal and professional readiness for social work practice (Robinson, 2018). Such programs are often an extension of the traditional classroom-based experience for students and provide applied outlets to demonstrate knowledge and practice skills (Andron, 2013; Mitschke \& Petrovich, 2011; Norris \& Schwartz, 2009). Many experiential techniques in social work education focus on enhancing macro-practice knowledge among students, such as social policy (Anderson \& Harris, 2005; Carey, 
2007; Pierpont et al., 2001; Scott, 2008; Sather et al., 2007). These techniques have the potential to produce more socially aware students with skills in community organizing and advocacy (Dailey et al., 2016), as well as the overall ability to create social change (Fineran et al., 2002).

\section{Application of the NASW Code of Ethics to experiential learning}

While there is no literature that directly links all six core values of the Code of Ethics - service, social justice, dignity and worth of the person, importance of human relationships, integrity, and competence - to learning outcomes associated with experiential learning techniques, many studies directly or indirectly apply at least one of these values. For instance, Mitschke and Petrovich (2011) describe a service-learning activity that exposed social work students to a community health clinic serving a diverse group of clients. Their findings indicate that these students developed a strong sense of civic responsibility (i.e., service) and advocacy (i.e., social justice) through their participation. Additional literature supports the use of experiential learning techniques to impact students' ability or willingness to challenge social injustice (see Cramer et al., 2012; Dailey et al., 2016; Fineran et al., 2002; Scott, 2008).

Another service-learning program described by Donaldson and Daughtery (2001) promoted strong community collaboration between social work students and low-income residents in Washington, D.C. This progressive model focused on developing dignity and worth of community members through their partnership (i.e., dignity and worth of the person). Pierpont and colleagues (2001) focused on developing related values among a group of social work students engaged in a policy-related service learning assignment. Similarly, in the poverty simulation project previous described (Vandsburger et al., 2010) social work students gained a better appreciation for the importance of human relationships.

Finally, there is much literature (Anderson \& Harris, 2005; Lemieux \& Allen, 2007; Norris \& Schwartz, 2009; Pierpont et al., 2001; Williams et al., 2002) that links experiential learning techniques to developing competent 
social work practitioners (i.e., competence). For instance, a study examined social work students' use of self through a reflective/experiential project that aided in their overall feelings of competence in the field (Taylor \& Cheung, 2010). In this course in which students were enrolled, they also reflected upon the use of self in application to various values and their derivative principles of the Code of Ethics. This demonstrates their ability to align themselves personally and professionally with the Code of Ethics and act in an ethical manner (i.e., integrity).

\section{Gap in the literature}

While the literature highly suggests the utilization of experiential learning activities in social work education to enhance overall knowledge and skills of students, to our knowledge there has been no research that has directly linked the use of such activities to the actual job readiness of students after they have entered the arena of social work practice. Therefore, the purpose of this study was to assess how an experiential learning program played a role in social work students' preparation for social work practice, once they have entered the workforce. The Code of Ethics was used to this guide analysis, whereas study findings are described in the context of each of the core values. We propose that utilizing the NASW (2021) Code of Ethics can be a meaningful method for gauging the impact of experiential learning programs, since these are the core values, principles, and ethical standards which we are expected to uphold in practice.

\section{Methods}

\section{Description of the immersion learning course}

Participants in this study had all completed a social work immersion learning course when enrolled as BSW students at a large Midwestern university. The purpose of this 15-week elective course was to explore social and political perspectives on racism, sexism, and classism as they pertain to poverty in the United States. The course prepared students for an intensive 
immersion experience in Portland, Oregon, which involved learning about the long-term social and political effects of poverty, including issues of homelessness, youth runaways, welfare, drug addiction, sexual exploitation, and the long-term impact on children, families, and communities. The role of social workers in addressing the social injustices in this community was also explored. While in Portland, the students worked with and learned from the members of various organizations about the types of political and social advocacy work they were engaging in to address social issues in their community.

Ten social work and pre-social work students were selected to participate in this course each year. An application and interview process were conducted to select students. Students participated in three pre-trip and two post-trip seminars and were required to complete written assignments based upon course readings. Students also kept a daily reflection journal during their time in Portland.

While on the trip, students visited a number of community-based organizations, such as meal service programs, long-term drug rehabilitation centers, permanent housing agencies, street outreach programs, community organizing organizations, and a permanent tent city, to learn from the organizational staff and clients. Service-based activities, such as serving meals, distributing clothes and supplies, gardening, and assisting organizations in other tasks were also scheduled. Each evening was devoted to a large group reflection session of the students' experiences that day. These sessions were facilitated by the course instructors and would last anywhere from one to three hours, depending on the depth of processing required by the students. The primary investigator of this study and one of the co-authors were instructors for this immersion learning course between the years of 2013-2015 (Robinson) and 2011-2015 (Bobst).

\section{Data collection}

Semi-structured, one-on-one interviews were conducted with study participants. Interviews were conducted by a trained research assistant, who had 
no prior involvement with the study participants nor the immersion learning course. Participants were recruited through a study flyer, distributed to former students who had completed this immersion course. Interviews lasted approximately 30 minutes and were conducted over the phone. Interviews were audio recorded and transcribed verbatim by a professional transcription company. Participants received a $\$ 20$ gift card taking part in this study.

An interview guide was used to lead the question-asking process. This guide was informed by expertise of the study team, and prior teaching experience of the instructors for the immersion course. The interview guide included three sections of questions: 1) demographic and background information; 2) overall impact of the course; and 3) specific impact of the course on the participants' social work career. In part, interview guide questions inquired about how the immersion course had impacted the participants' short-term and long-term career path and goals. In addition, participants were also asked about how the course impacted their view and understanding of the Code of Ethics and how they adhere to these ethical values in their careers post-graduation.

\section{Analysis}

Transcribed interviews were entered into the qualitative analysis software, Nviv012, and analyzed. As the Code of Ethics was used to craft interview questions, it was also used to guide the analysis process. Therefore, a deductive coding approach was used in this research (Elo \& Kyngäs, 2008) whereas the six ethical values of the Code of Ethics were defined as initial codes. These values are: 1) Service; 2) Social Justice; 3) Dignity and Worth of the Person; 4) Importance of Human Relationships; 5) Integrity; and 6) Competence. Each transcript was coded by two trained researchers. Analysis was an iterative process, in which divergent coding was thoroughly discussed in a consensus building process to achieve strong interrater reliability. Cohen's Kappa was used to calculate interrater reliability, and at the end 
of the coding process each code demonstrated strong interrater reliability (Range: 0.70-1.0), with an overall Kappa of 0.95 .

To help ensure study findings were consistent with participants' experiences, member checking methods were utilized (Lincoln \& Guba, 1985; Creswell, 1994). The results of this research were shared with three study participants for review. Individually, each of these participants stated that the study findings were consistent with their experiences while enrolled in the immersion course and the impact the course has had on their social work careers post-graduation. All study activities were approved by the university institutional review board prior to recruitment and data collection.

\section{Results}

Twenty participants completed an interview with the study team. Participants ranged in age from 22 to 42 years, and the majority identified as white $(n=18,90 \%)$ and female ( $n=15,75 \%)$. All participants had participated in the immersion learning course between the years of 2011 and 2016. For most participants ( $n=16,80 \%)$, this immersion course was the only immersion experience in which they had participated. For the other four participants, they had participated in other forms of non-social work immersion or service-learning opportunities prior to enrolling in this course. Of the participants, 13 (65\%) had either completed or were working on completing their MSW degree at the time of their interview. Participants reported working in a variety of social work disciplines, including behavioral health services, grant writing and development, substance abuse counseling, domestic violence, medical social work, school social work, and case management, among others.

Participants were asked questions regarding the impact of this immersion learning course on their social work career, including how it has impacted their understanding and application the Code of Ethics in their careers. Therefore, findings from this study will be presented in context of the six ethical values of the NASW (2021) Code of Ethics. 


\section{Service}

Nine participants (45\%) identified that this immersion learning course had an impact on their understanding of and how they adhere to the ethical value of Service. Participants highlighted the importance of using their training in social work, as well as their privilege, to provide service to people in need. Many participants reflected upon volunteer work they performed while on the immersion trip (such as serving food or volunteering at a day shelter), and stated these experiences helped them understand the value of volunteerism outside of their paid employment.

For participants who do not currently work with individuals experiencing homelessness, this immersion course helped reinforce the many ways in which they could give back to and volunteer on behalf of this population. Some participants discussed volunteering at food programs and other homeless outreach programs during the evenings and weekends. For instance, one participant said that she began volunteering with a housing first program because "there are a few programs in the [city] area that are working towards housing first, and it's often getting shut down and the voices aren't being heard... so it's been my interest to get involved because it doesn't have enough support."

\section{Social Justice}

All 20 participants (100\%) identified that this immersion learning course had an impact on their understanding of and how they adhere to the ethical value of Social Justice. The immersion learning course had a strong macro social work and social justice focus, therefore all the participants in this study demonstrated that they have been able to apply what they gained from the course, in terms of this ethical value, to their careers. One participant who works as a school social worker said, "Oppression is a huge piece of what people experiencing homelessness face. Why are the kids that I am working with experiencing this problem? It is not something that any 12-year old should have to worry about." Another participant who is employed as a therapist said: 
Everyone says, 'why don't they just get a job?' Okay, well, first of all the unemployment rate in general is pretty high. And you go fill out an application and they make you put your address on there, well you don't have an address and you don't have a phone. How are you going to get contacted? How are you going to get to the interview? How are you going to get new clothes?

Another participant said that she was able to better understand how social justice issues impact a person in their home environment. She talked about the immersion course helping her to understand this and apply it to her job. In part, she said:

Something that I have noticed is, that I can work with a kid all day and I can make great changes and strides with the kid. And I send them home to that same environment, and they come back the next day, doing the exact same thing that we talked about and they worked through. You know? Because they're going back to that same environment. It helps me to understand why their environment impacts the way they are.

\section{Dignity and Worth of the Person}

Seventeen participants (85\%) identified that this immersion learning course had an impact on their understanding of and how they adhere to the ethical value of Dignity and Worth of the Person. In fact, participants had a lot to say regarding this ethical value. In their interviews, many participants referenced the various social service agencies in which they visited while on the immersion trip. They talked about how these agencies served as a model for their current careers, in how they uphold this ethical value and regard their clients. One participant in particular, who was questioning his decision to enter the field of social work prior to the immersion course, discussed how these agency visits helped him understand just how much social service agencies care about their clients and value their clients' worth. These visits helped reaffirm his commitment to social work.

Other participants also discussed how this immersion course helped them realize their biases towards individuals experiencing poverty and 
homelessness, and the judgement they unwittingly passed. One student in particular expressed how he did not realize his biases prior to enrolling in the immersion course, even though the topic was frequently discussed in his social work courses. However, now he believes that he is more self-aware in his job as a therapist.

Some participants also expressed how they were better able to understand the importance of client self-determination in their current work with clients. For many participants who completed this immersion course as a BSW student, they lacked social work job experience that highlighted the importance of client self-determination. It wasn't until the immersion trip in which they saw firsthand how empowering it can be for clients to have self-determination in their change process. One participant commented, "I would say that self-determination is a huge... because a lot of times people experiencing homelessness are notallowed to have that self-determination and they are just given handouts and expected to take what is given to them and not have a say."

And finally, other participants also talked about the importance of promoting dignity and worth of the person, through using person-first language. Using person-first language was encouraged in the immersion course and modeled by the course instructors. One participant said:

In my professional world I think about [person-first language] on a weekly basis. I know to phrase my words differently, like as a whole, not just in certain circumstances. But since [the immersion trip], like for example, I only use person first language, so it is never a homeless guy, it's a man experiencing homelessness. I think that's a piece of cultural competency.

\section{Importance of Human Relationships}

Seventeen participants (85\%) identified that this immersion learning course had an impact on their understanding of and how they adhere to the ethical value of Importance of Human Relationships. When speaking about this ethical value, there was much overlap in participants' responses to the 
prior value of Dignity and Worth of the Person. For instance, one participant said, "People [experiencing homelessness] are really made to feel invisible by society, and that's not fair because they have so much to bring to the table. We can learn from them."

Participants widely discussed how building relationships with clients can strengthen the helping process and enhance overall client well-being. One participant commented about how she was able to apply this ethical value to her job as a behavioral health provider for children. She said, "I think that's been my number one goal with families, is like 'how do I make this relationship important and make them feel worthy, so they feel empowered to do these things and give them hope?' I think that is my role specifically, that's the biggest tool we have." Another participant commented:

Relationship building, that's the most important thing. So, what if this kid isn't meeting his goal that I wrote down on paper? I mean, the fact that he's coming in and talking to me and feels comfortable sharing some of his struggles with me, I mean that is just the most important thing. It's that relationship piece.

\section{Integrity}

Nine participants (45\%) identified that this immersion learning course had an impact on their understanding of and how they adhere to the ethical value of Integrity. For this ethical value, participants seemed to find difficulty in explicitly stating or finding examples of how they apply this value to their current career. However, they demonstrated their adherence to this value in how they responded to many of the interview questions. Many participants in general talked about how this immersion course helped build their awareness of the Code of Ethics, and how social workers abide by these ethics. A few participants discussed the importance of social work integrity in upholding client confidentiality. One participant in particular who is an HIV case manager discussed this, as well as self-determination of the client and how that relates to social work integrity. She said: 
I have had many times where I think, in my head, that this choice isn't going to turn out well for [my client]. But I can't change anything, I am not going to force them. I am not going to threaten them with no services. It's just their choice, they have to make it. And it's allowing them to have the freedom to do that. And continuing to work with them to help them overcome.

\section{Competence}

All 20 participants (100\%) identified that this immersion learning course had an impact on their understanding of and how they adhere to the ethical value of Competence. Participants overwhelmingly discussed how being exposed to issues such as homelessness and poverty through an immersion course facilitated their competency in social work delivery. In general, participants seemed to appreciate the opportunity to learn outside of a classroom and apply what they had learned in a classroom setting to real situations of people experiencing homelessness. For instance, one participant commented, "So I think [the immersion course] just kind of solidified the things that we learned in the classroom." Another participant had similar thoughts:

There really is no better way to learn than talking with the people experiencing those problems and seeing the organizations that are trying to assist these people. Hearing from organizations - this is what works for us, this is what doesn't, and this is what our clients want-you know. I think just exposure is the best way to learn.

However, some students talked about specific things they learned while enrolled in the immersion course and how they have used the knowledge in their current practice. One participant who has worked with at-risk youth since she participated in the trip said:

It made me realize there is a lot of homeless youth out there as well, and a lot of them are runaways from, like, maybe problems at home. And it's not like they are bad kids. Like some might think they are bad kids, like what is wrong with them? But a lot of the times they have a lot of issues at home and that is why they just chose to be homeless rather than to 
live in an abusive relationship. That is one of major things that I learned that I did not necessarily know before.

\section{Discussion}

As the findings suggest, all students who participated in this immersion course experienced a strengthened understanding of the social justice value. The purpose of the structured activities and visiting the selected organizations provided an intentional set of meaningful guideposts to demonstrate social justice in action, in various forms. Therefore, the finding that the social justice value was strengthened for students is not surprising and further reinforces existing evidence (Cramer et al., 2012; Dailey et al., 2016; Fineran et al., 2002; Mitschke \& Petrovich, 2011; Scott, 2008). However, participants' ability to apply that value post-graduation into their careers is very important. The majority of our sample currently works in microlevel practice settings, and all students reported an ability to apply this ethical value to their daily social work practice.

Similarly, dignity and worth of the person was highly emphasized in the course. Therefore, this finding is not necessarily surprising but lends insight on using immersion learning as a teaching mechanism to strengthen this value with our students. Since our participants are micro-focused in their careers, this is how they applied this ethical value to their careers and with their individual clients. Visiting the various organizations in Portland afforded students the opportunity to work and learn directly from individuals experiencing poverty, homelessness and sexual exploitation.

In addition, many of the organizations adopted a progressive model of social service delivery, which also promoted human dignity and importance of human relationships. An example would include a meal site which served patrons in a restaurant style, rather than a traditional soup kitchen line. These simple acts elevate the dignity and worth of every person. Removing the stigma and isolation that accompanies poverty and homelessness, the organizations and activities on the immersion trip focused on recognizing and enhancing the importance of human relationships. Exposing students 
to these types of service delivery models provided insight to show how these values can be applied. The majority of our participants were not working directly or solely with individuals experiencing homelessness, yet through the immersion course, they had been instilled with a commitment to this population. Many know that they will likely come in contact with lower income or homeless clients in their social work careers, and this trip has armed them with tools and skills to effectively and compassionately deliver services to meet their needs. The use of progressive models to teach about social work delivery, especially through experiential techniques, has also been documented in the literature as an effective approach (Donaldson \& Daughtery, 2001).

The finding related to competence was somewhat surprising to the research team. We did not expect to see perceived confidence in individual competence to increase with all students. Many students however, commented that this immersion course was their first exposure to social service models, individuals experiencing poverty, homelessness, and sexual exploitation, and even their first trip outside of their community. As the findings indicate, students being able to see core values and principles applied in the field created a stronger sense of competence. This level of preparation was significant for participants' growing skillset and confidence to practice in the field of social work. This finding underscores Kolb's Experiential Learning Theory (Kolb, 1984), in that the integration of concrete experiences with reflective observation assisted the students in developing a critical understanding and application of their experiences/skillset post-graduation. These results reinforce that immersion courses and other similar trips can be a valuable mechanism for strengthening competence among our social work students and their post-graduation careers.

While other studies have found an impact on students' sense of civic duty (e.g., Mitschke \& Petrovich, 2011) due to experiential techniques, the value of service was not strengthened as significantly as the other five principles for our participants. This is unsurprising, given that the main focus of the immersion trip was geared towards social justice and addressing systemic and root causes of poverty and homelessness. However, some 
participants did discuss that they were inspired to engage in volunteer work, outside of their paid employment, due to this immersion course. As for the value of integrity, similarly, it was not explicitly identified by all students as an area that was strengthened. Our research team believes if this value had been more explicitly explored during the immersion trip, participants' responses would have shown a strengthening of this value.

More BSW education programs should consider adopting immersion learning or other types of experiential learning techniques into their curricula. A particular focus on enhancing the six core values of the Code of Ethics will result in students feeling more prepared for the workforce. In addition, such programs can foster in-depth understanding of complex issues such as poverty, homelessness and sexual exploitation on behalf of students. This will also help improve and maintain the integrity of our profession. When students learn about a concept, see it in action, and understand it, they will apply that concept more readily in their future practice.

\section{Limitations}

This study is limited in generalizability due to the small sample size and geographic heterogeneity of the students enrolled in the immersion learning course. Students also self-selected into the study sample, which may have influenced the findings. For instance, students who gained more out of this immersion course may have decided to participate in this study, which would influence the findings on their understanding and application of the Code of Ethics. In addition, while this study attempted to control for investigator bias in multiple ways, the findings may still be subject to the interpretation of the study team. 


\section{Conclusion}

This qualitative study examined the impact of an immersion learning course on social work students' understanding and application of the NASW (2021) Code of Ethics to their social work careers, post-graduation. Findings further reinforce the utility of such experiential learning programs for social work students to better prepare them for practice. We suggest that explicitly using the Code of Ethics as a teaching tool to help students apply knowledge to practice can help enhance their skill and adherence to these ethical values, principles, and standards.

\section{References}

Anderson, D. K., \& Harris, B. M. (2005). Teaching social welfare policy: A comparison of two pedagogical approaches. Journal of Social Work Education, 41(3), 511-526.

Andron, S. (2013). Rebuilding New Orleans: A community field learning experience. Journal of Teaching in Social Work, 33(3), 297-307.

Carey, L. A. (2007). Teaching macro practice: An experiential learning project. Journal of Teaching in Social Work, 27(1-2), 61-71.

Cleary, D. (2001). Oppression, power, inequality: An interdisciplinary approach. Teaching Sociology, 29(1), 36-47.

Cramer, E. P., Ryosho, N., \& Nguyen, P. V. (2012). Using experiential exercises to teach about diversity, oppression, and social justice. Journal of Teaching in Social Work, 32(1), 1-13.

Creswell, J. W. (1998). Qualitative Inquiry and Research Design Choosing Among Five Traditions. Sage Publications.

Dailey, A. L., Washington, K. T., \& Havig, K. (2016). Brown lettuce and rodent traps, granola and trees: A qualitative study of an experiential teaching tool to promote socially just practice. The Journal of Social Work Values and Ethics, 13(2), 47-55.

Dewey, ]. (1938). Experience and education. MacMillan. 
Donaldson, L. P., \& Daughtery, L. (2011). Introducing asset-based models of social justice into service learning: A social work approach. Journal of Community Practice, 19(1), 80-99.

Elo, S., \& Kyngäs, H. (2008). The qualitative content analysis process. Journal of Advanced Nursing, 62(1), 107-115.

Fineran, S., Bolen, R. M., Urban-Keary, M., \& Zimmerman, L. (2002). Sharing common ground: Learning about oppression through an experiential game. Journal of Human Behavior in the Social Environment, 6(4), 1-19.

Kolb, D. (1984). Experiential learning: Experience as the source of learning and development. Upper Saddle River.

Lincoln, Y. S., \& Guba, E. G. (1985). Naturalistic Inquiry. Sage Publications.

Lemieux, C. M., \& Allen, P. D. (2007). Service learning in social work education: The state of knowledge, pedagogical practicalities, and practice conundrums. Journal of Social Work Education, 43(2), 309-326.

Maccio, E. M. (2011). Graduate social work students' attitudes toward service-learning. Journal of Teaching in Social Work, 31(2), 163-177.

Milne, A., \& Adams, A. (2015). Enhancing critical reflection amongst social work students: The contribution of an experiential learning group in care homes for older people. Social Work Education, 34(1), 74-90.

Mitschke, D. B., \& Petrovich, J. C. (2011). Improving social work students' understanding of health and social justice knowledge through the implementation of service learning at a free community health clinic. Journal of Human Behavior in the Social Environment, 21 (1), 97108.

NASW [National Association of Social Workers]. (2021, February). Code of Ethics of the National Association of Social Workers. Retrieved from: https://www.socialworkers.org/About/Ethics/Code-of-Ethics

Norris, D. S., \& Schwartz, C. L. (2009). Needs assessments: An integrated assignment in civic service. Journal of Teaching in Social Work, 29(4), 373-382. 
Pierpont, J. H., Pozzuto, R., \& Powell, ]. Y. (2001). Service learning and systems of care: Teaching students to learn from clients. Journal of Family Social Work, 5(3), 79-93.

Pugh, G. L. (2014a). The experiential learning cycle in undergraduate diversity and social justice education. Journal of Teaching in Social Work, 34(3), 302-315.

Pugh, G. L. (2014b). Revisiting the pink triangle exercise: An exploration of experiential learning in graduate social work education. Journal of Teaching in Social Work, 34(1), 17-28.

Robinson, E. L. (2018). Immersion Learning in Social Work Education: A Pedagogical Tool for Enriching Knowledge and Practice Skills among BSW Students. Journal of Teaching in Social Work, 38(5), 536550.

Sanders, S., McFarland, P., \& Bartolli, J. S., (2003) The impact of cross-cultural service-learning on undergraduate social work students' perceptions of culture, race and economic justice. Journal of Baccalaureate Social Work, 9(1), 19-40.

Sather, P., Weitz, B., \& Carlson, P. (2007). Engaging students in macro issues through community-based learning: The policy, practice, and research sequence. Journal of Teaching in Social Work, 27(3-4), 61-79.

Saunders, J. A., Haskins, M., \& Vasquez, M. (2015). Cultural competence: A journey to an elusive goal. Journal of Social Work Education, 51(1), 1934.

Schelbe, L., Petracchi, H. E., \& Weaver, A. (2014). Benefits and challenges of service-learning in baccalaureate social work programs. Journal of Teaching in Social Work, 34(5), 480-495.

Scott, D. L. (2008). Service learning: The road from the classroom to community-based macro intervention. Journal of Policy Practice, 7(2-3), 214-225. 
Taylor, P. G., \& Cheung, M. (2010). Integration of personal/professional self (IPPS) through reflective/experiential learning. Journal of Teaching in Social Work, 30(2), 159-174.

Vandsburger, E., Duncan-Daston, R., Akerson, E., \& Dillon, T. (2010). The effects of poverty simulation, an experiential learning modality, on students' understanding of life in poverty. Journal of Teaching in Social Work, 30(3), 300-316.

Williams, N. R., King, M., \& Koob, J. J. (2002). Social work students go to camp: The effects of service learning on perceived self-efficacy. Journal of Teaching in Social Work, 22(3-4), 55-70. 